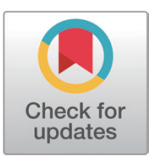

Received: Jan 26, 2021

Revised: Feb 2, 2021

Accepted: Feb 4, 2021

*Corresponding author Sungsue Rheem

Graduate School of Public Administration, Korea University,

Sejong 30019, Korea.

Tel: +82-44-860-1554

E-mail: rheem@korea.ac.kr

Sejong Oh

Department of Animal Science,

Chonnam National University, Gwangju

61186, Korea.

Tel: +82-62-530-2116

E-mail: soh@jnu.ac.kr

Copyright $\odot 2021$ Korean Society of Animal Sciences and Technology.

This is an Open Access article distributed under the terms of the Creative Commons Attribution

Non-Commercial License (http:// creativecommons.org/licenses/by$\mathrm{nc} / 4.0 /$ ) which permits unrestricted non-commercial use, distribution, and reproduction in any medium, provided the original work is properly cited.

ORCID

Thi Duyen Dang

https://orcid.org/0000-0002-4202-8808

Cheng Chung Yong

https://orcid.org//0000-0003-0531-6381

Sungsue Rheem

https://orcid.org/0000-0001-7009-3343

\section{Optimizing the composition of the medium for the viable cells of Bifidobacterium animalis subsp. lactis JNU306 using response surface methodology}

\author{
Thi Duyen Dang ${ }^{1,2}$, Cheng Chung Yong ${ }^{1}$, Sungsue Rheem ${ }^{3 *}$ and Sejong $\mathrm{Oh}^{1 *}$ \\ ${ }^{1}$ Department of Animal Science, Chonnam National University, Gwangju 61186, Korea \\ ${ }^{2}$ Western Highlands Agriculture and Forestry Science Institute, Buon Ma Thuot, Dak Lak Province \\ 63161, Viet Nam \\ ${ }^{3}$ Graduate School of Public Administration, Korea University, Sejong 30019, Korea
}

\begin{abstract}
This research improved the growth potential of Bifidobacterium animalis subsp lactis strain JNU306, a commercial medium that is appropriate for large-scale production, in yeast extract, soy peptone, glucose, L-cysteine, and ferrous sulfate. Response surface methodology (RSM) was used to optimize the components of this medium, using a central composite design and subsequent analyses. A second-order polynomial regression model, which was fitted to the data at first, significantly lacked fitness. Thus, through further analyses, the model with linear and quadratic terms plus two-way, three-way, and four-way interactions was selected as the final model. Through this model, the optimized medium composition was found as $2.8791 \%$ yeast extract, $2.8030 \%$ peptone soy, $0.6196 \%$ glucose, $0.2823 \%$ L-cysteine, and $0.0055 \%$ ferrous sulfate, $w / v$. This optimized medium ensured that the maximum biomass was no lower than the biomass from the commonly used blood-liver (BL) medium. The application of RSM improved the biomass production of this strain in a more cost-effective way by creating an optimum medium. This result shows that $B$. animalis subsp lactis JNU306 may be used as a commercial starter culture in manufacturing probiotics, including dairy products.
\end{abstract}

Keywords: Bifidobacterium animalis, Medium, Yeast extract - Soy Peptone - Glucose (YPG), Optimization, Response surface methodology (RSM)

\section{INTRODUCTION}

Bifidobacteria is indicated to affect the gastrointestinal health of humans and animals significantly. Numerous intensive studies have been conducted on gut health in relation to these bacteria [1]. These studies have enabled the use of bifidobacteria as probiotic strains, which are live beneficial microflora orally administered to humans for their dominance in the intestine.

The third commonly used genus in probiotics application, bifidobacteria were first used by Mayer 
Sejong Oh

https://orcid.org/0000-0002-5870-3038

Competing interests

No potential conflict of interest relevant to

this article was reported.

Funding sources

This work was financially supported by the Graduate School of Public Administration at Korea University in 2020. And also this work was supported by the Basic Science Research Program through the National Research Foundation of Korea (NRF) funded by the Minister of Education, Science, and Technology (NRF-2016R1A2B4007519 and NRF-2019R1A2C108764811).

Acknowledgements

Not applicable.

\begin{abstract}
Availability of data and material Upon reasonable request, the datasets of this study can be available from the corresponding author.
\end{abstract}

\section{Authors' contributions}

Conceptualization: Oh S.

Data curation: DangTD.

Formal analysis: Rheem S.

Methodology: DangTD.

Software: Rheem S.

Validation: DangTD, Yong CC.

Investigation: DangTD.

Writing-original draft: DangTD, Yong CC, Rheem S.

Writing-review \& editing: Rheem S, Oh S.

Ethics approval and consent to participate This article does not require IRB/IAUCUC approval because there are no human and animal participants. in 1949 in making baby food. Later in 1968, Schuler Malyoth and his colleague showed that this bacterium can also be cultivated in dairy products [1], and the bacteria gained importance in the industry due to many health benefits. For only a few past decades, hundreds of bifidobacteriacontaining foods have been produced and made available under trademarks worldwide [2].

One of the widest uses of bifidobacteria in probiotic products is their inclusion in dairy products that have been historically consumed by humans [3]. Regarding this, Bifidobacterium animalis subsp. lactis is the most widely used Bifidobacterium species. They appear in various arrays of dietary supplements and foods, especially fermented milk and junk foods. This organism is also considered the organism of choice technologically due to the high survival ability in the human gastrointestinal tract, and better feasibility compared to other bifidobacteria [4-7]. Therefore, it is important that we cultivate B. animalis subsp. lactis on a large-scale for manufacturing.

Bifidobacterium animalis subsp. lactis is possibly the best-known of the Bifidobacterium family, which requires nutrition media containing numerous amino acids, vitamins and related growth factors, for instance low oxidation and miner components [8]. Although various bifidobacteria growth media has been studied, these are unsuitable for large-scale production due to low cell mass production, unavailable materials, complex process, cost, and difficult harvesting problems $[1,8,9]$. Therefore, prevalent commercial media, which can limit the defects of previous ones, are required.

Yeast extract - Soy Peptone - Glucose (YPG) medium is considered a nutrient medium with rich amino acid and carbohydrate deposits [10], and with the addition of growth stimulated factors such as L-cysteine and Ferrous sulfate, YPG meets the requirements for the production of mass cell concentrations of bifidobacteria. Moreover, by using inexpensive materials, a new medium should be cost-effective and feasible during manufacturing.

Besides, one of the major components in designing new fermentation media is numerous experiments. Response surface methodology (RSM) is a collection of statistical and mathematical techniques including factual designs and regression analysis, which is more suitable for accessing multifactor experiments [11-13]. Therefore, using RSM provides a unique solution to determine the optimized growth conditions of Bifidobacterium in YPG medium.

This study outlines the optimized mass cell production of B. animalis subsp. lactis JNU306 in Yeast extract-Peptone Soy-Glucose -based medium using RSM.

\section{MATERIALS AND METHODS}

\section{Microorganism and growth media}

Bifidobacterium animalis subsp. lactis strain JNU306 was originally isolated from infant feces and used as a freeze storage strain at Chonnam National University. The Skim Milk medium [14] and blood-liver (BL) medium [15] were used as storage and activation media, respectively, for B. animalis subsp. lactis JNU306. This strain was stored at $-70^{\circ} \mathrm{C}$. The bacterium was activated by inoculating a colony in BL medium anaerobically at $37^{\circ} \mathrm{C}$ for $48 \mathrm{~h}$. The strain was further propagated by incubating twice in $\mathrm{BL}$ broth to obtain a biomass concentration of $10^{8} \mathrm{CFU} / \mathrm{mL}$. To limit the carryover of the previous medium, the culture was centrifuged at 3,000 $\mathrm{rpm}$ for $15 \mathrm{~min}$ at $4^{\circ} \mathrm{C}$ to harvest cells, and the cells were resuspended in the same medium before incubating $(0.1 \%)$ in various media.

\section{Preparation of experimental media and fermentation conditions}

The test media components used in the experiment comprised yeast extract (HY-YEST 501, Kerry bioscience, Beloit, WA, USA), peptone soy (Peptone S, Daejung, Siheung, Korea), glucose (D[+]glucose, Junsei, Tokyo, Japan), L-cysteine (L-cysteine hydrochloride monohydrate, Sigma, St. 
Louis, MO, USA) and ferrous sulfate (Iron (II) Sulfate, Wako, Richmond, VA, USA). The media were autoclaved at $121^{\circ} \mathrm{C}$ for 15 minutes and cooled to room temperature before inoculation with cell pellets. The culture was incubated in 50-mL screw cap glass tubes (Cole-Parmer, Montreal, QC, Canada) containing $30 \mathrm{~mL}$ of broth and $5 \mathrm{~mL}$ of paraffin liquid to create an anaerobic environment. The fermentation was conducted in a water bath at $37^{\circ} \mathrm{C}$ for $24 \mathrm{~h}$ and at $\mathrm{pH}$ 7.0-7.2.

\section{Microbial analysis}

Viable cell enumeration was performed by diluting samples several times in a buffered saline solution containing (in $\mathrm{g} / \mathrm{L}$ ): potassium phosphate monobasic 4.5; sodium phosphate dibasic, 6; L-cysteine, 0.5 , and Tween $80,0.5$. The resulting mixture was stirred using a magnetic stirrer until absolute homogenization to give a 10-fold dilution (wet weight/volume). Aliquots $(1 \mathrm{~mL})$ of each dilution were evenly spread on plates of freshly prepared $\mathrm{BL}$ media. Plates were incubated at $37^{\circ} \mathrm{C}$ for $48 \mathrm{~h}$ by both methods of anaerobic jars and steel wool in anaerobic incubator (Anarorator, Hanteck, Uiwang, Korea) and anaerobic packs (AnaeroPack, Mitsubishi Gas Chemical, Tokyo, Japan).

\section{Experimental design and data}

The culture medium was incubated after various treatment combinations under anaerobic conditions at $37^{\circ} \mathrm{C}$ for $24 \mathrm{~h}$. After incubation, the number of viable cells was estimated by plate counting. Bacterial growth was tested with $30 \mathrm{~mL}$ volumes of medium in a $50-\mathrm{mL}$ tube. For the factors for our response surface experiment, peptone soy, yeast extract, glucose, L-cysteine, and ferrous sulfate were selected. As our response surface design, the five-level-five-factor central composite design (CCD) was chosen. Table 1 displays the factors and their levels in our CCD. Table 2 shows our CCD, which consists of 32 factorial, 10 axial, and 6 center runs, and the responses from these 48 runs. The responses represent maximum biomass counts at $24 \mathrm{~h}$. With $\log _{10} \mathrm{CFU} /$ $\mathrm{mL}$ as their unit, the responses ranged from 7.99 to 10.29 .

\section{Statistical analysis}

Data were analyzed using SAS software. SAS/STAT [16] was employed for the statistical modeling of the data. Graphs were produced using SAS/GRAPH [16].

\section{RESULTS}

\section{Developing an analysis model}

First, the second-order polynomial regression model was used to model the experimental data in Table 2. However, this model turned out to be inadequate, as indicated by the analysis of variance (Table 3); the model was non-significant $(p=0.1116>0.05)$, the $r^{2}$ was low $\left(r^{2}=0.5501\right)$, and the

Table 1. Factors and their levels in our central composite design (CCD)

\begin{tabular}{lccccc}
\hline \multirow{2}{*}{ Actual factor (Coded factor) } & \multicolumn{5}{c}{ Actual factor level corresponding to the coded factor level } \\
\cline { 2 - 6 } & $\mathbf{2 . 3 6 6}$ & $\mathbf{- 1}$ & $\mathbf{0}$ & $\mathbf{1}$ & $\mathbf{2 . 3 6 6}$ \\
\hline Peptone soy $\left(\mathrm{X}_{1}\right)(\%[\mathrm{w} / \mathrm{v}])$ & 0.000 & 1.155 & 2.000 & 2.845 & 4.000 \\
Yeast extract $\left(\mathrm{X}_{2}\right)(\%[\mathrm{w} / \mathrm{v}])$ & 0.000 & 1.155 & 2.000 & 2.845 & 4.000 \\
Glucose $\left(\mathrm{X}_{3}\right)(\%[\mathrm{w} / \mathrm{v}])$ & 0.000 & 0.577 & 1.000 & 1.423 & 2.000 \\
L-cystein $\left(\mathrm{X}_{4}\right)(\%[\mathrm{w} / \mathrm{v}])$ & 0.000 & 0.289 & 0.500 & 0.711 & 0.100 \\
Ferrous sulfate $\left(\mathrm{X}_{5}\right)(\%[\mathrm{w} / \mathrm{v}])$ & 0.000 & 0.006 & 0.010 & 0.014 & 0.020 \\
\hline
\end{tabular}


Table 2. CCD in coded factor levels and maximum biomass as the response

\begin{tabular}{|c|c|c|c|c|c|c|c|}
\hline Run & $\begin{array}{l}\text { Treat- } \\
\text { ment }\end{array}$ & $\begin{array}{c}\text { Peptone soy } \\
\left(X_{1}\right)\end{array}$ & $\begin{array}{c}\text { Yeast } \\
\text { extract }\left(X_{2}\right)\end{array}$ & $\begin{array}{c}\text { Glucose } \\
\left(\mathrm{X}_{3}\right)\end{array}$ & $\begin{array}{l}\text { L-cystein } \\
\left(\mathrm{X}_{4}\right)\end{array}$ & $\begin{array}{l}\text { Ferrous } \\
\text { sulfate }\left(X_{5}\right)\end{array}$ & $\begin{array}{c}\text { Maximum } \\
\text { biomass }\left(Y^{1)}\right)\end{array}$ \\
\hline 1 & 1 & -1 & -1 & -1 & -1 & -1 & 7.99 \\
\hline 2 & 2 & -1 & -1 & -1 & -1 & 1 & 9.06 \\
\hline 3 & 3 & -1 & -1 & -1 & 1 & -1 & 9.15 \\
\hline 4 & 4 & -1 & -1 & -1 & 1 & 1 & 9.38 \\
\hline 5 & 5 & -1 & -1 & 1 & -1 & -1 & 9.68 \\
\hline 6 & 6 & -1 & -1 & 1 & -1 & 1 & 8.92 \\
\hline 7 & 7 & -1 & -1 & 1 & 1 & -1 & 9.23 \\
\hline 8 & 8 & -1 & -1 & 1 & 1 & 1 & 9.19 \\
\hline 9 & 9 & -1 & 1 & -1 & -1 & -1 & 9.35 \\
\hline 10 & 10 & -1 & 1 & -1 & -1 & 1 & 9.11 \\
\hline 11 & 11 & -1 & 1 & -1 & 1 & -1 & 10.12 \\
\hline 12 & 12 & -1 & 1 & -1 & 1 & 1 & 9.45 \\
\hline 13 & 13 & -1 & 1 & 1 & -1 & -1 & 9.30 \\
\hline 14 & 14 & -1 & 1 & 1 & -1 & 1 & 9.25 \\
\hline 15 & 15 & -1 & 1 & 1 & 1 & -1 & 9.39 \\
\hline 16 & 16 & -1 & 1 & 1 & 1 & 1 & 9.38 \\
\hline 17 & 17 & 1 & -1 & -1 & -1 & -1 & 9.17 \\
\hline 18 & 18 & 1 & -1 & -1 & -1 & 1 & 9.42 \\
\hline 19 & 19 & 1 & -1 & -1 & 1 & -1 & 9.39 \\
\hline 20 & 20 & 1 & -1 & -1 & 1 & 1 & 9.36 \\
\hline 21 & 21 & 1 & -1 & 1 & -1 & -1 & 9.07 \\
\hline 22 & 22 & 1 & -1 & 1 & -1 & 1 & 9.11 \\
\hline 23 & 23 & 1 & -1 & 1 & 1 & -1 & 9.32 \\
\hline 24 & 24 & 1 & --1 & 1 & 1 & 1 & 9.00 \\
\hline 25 & 25 & 1 & 1 & -1 & -1 & -1 & 10.29 \\
\hline 26 & 26 & 1 & 1 & -1 & -1 & 1 & 9.18 \\
\hline 27 & 27 & 1 & 1 & -1 & 1 & -1 & 9.45 \\
\hline 28 & 28 & 1 & 1 & -1 & 1 & 1 & 9.44 \\
\hline 29 & 29 & 1 & 1 & 1 & -1 & -1 & 9.39 \\
\hline 30 & 30 & 1 & 1 & 1 & -1 & 1 & 9.32 \\
\hline 31 & 31 & 1 & 1 & 1 & 1 & -1 & 9.44 \\
\hline 32 & 32 & 1 & 1 & 1 & 1 & 1 & 9.43 \\
\hline 33 & 33 & -2.366 & 0 & 0 & 0 & 0 & 9.03 \\
\hline 34 & 34 & 2.366 & 0 & 0 & 0 & 0 & 9.30 \\
\hline 35 & 35 & 0 & -2.366 & 0 & 0 & 0 & 8.54 \\
\hline 36 & 36 & 0 & 2.366 & 0 & 0 & 0 & 9.44 \\
\hline 37 & 37 & 0 & 0 & -2.366 & 0 & 0 & 9.19 \\
\hline 38 & 38 & 0 & 0 & 2.366 & 0 & 0 & 9.11 \\
\hline 39 & 39 & 0 & 0 & 0 & -2.366 & 0 & 9.31 \\
\hline 40 & 40 & 0 & 0 & 0 & 2.366 & 0 & 9.61 \\
\hline 41 & 41 & 0 & 0 & 0 & 0 & -2.366 & 9.16 \\
\hline 42 & 42 & 0 & 0 & 0 & 0 & 2.366 & 9.18 \\
\hline 43 & 43 & 0 & 0 & 0 & 0 & 0 & 9.20 \\
\hline 44 & 43 & 0 & 0 & 0 & 0 & 0 & 9.34 \\
\hline 45 & 43 & 0 & 0 & 0 & 0 & 0 & 9.35 \\
\hline 46 & 43 & 0 & 0 & 0 & 0 & 0 & 9.31 \\
\hline 47 & 43 & 0 & 0 & 0 & 0 & 0 & 9.33 \\
\hline 48 & 43 & 0 & 0 & 0 & 0 & 0 & 9.16 \\
\hline
\end{tabular}

${ }^{1)}$ Maximum biomass count achieved at $20 \mathrm{~h}$, expressed in $\log _{10} \mathrm{CFU} / \mathrm{mL}$. CCD, central composite design. 
Table 3. Analysis of variance for the initial model

\begin{tabular}{lrcccc}
\hline \multicolumn{1}{c}{ Regression } & DF & Type 1 sum of squares & $\boldsymbol{R}$-square & $\boldsymbol{F}$-value & $\boldsymbol{p}$-value \\
\hline Linear & 5 & 1.601320 & 0.3190 & 3.83 & 0.0095 \\
Quadratic & 5 & 0.234238 & 0.0467 & 0.56 & 0.7296 \\
2-Way interactions & 10 & 0.926281 & 0.1845 & 1.11 & 0.3920 \\
Total model & 20 & 2.761839 & 0.5501 & 1.65 & 0.1116 \\
\hline \multicolumn{1}{c}{ Residual } & DF & Sum of squares & Mean square & $\boldsymbol{F}$-value & $\boldsymbol{p}$-value \\
\hline Lack of fit & 22 & 2.225909 & 0.101178 & 15.48 & 0.0032 \\
Pure error & 5 & 0.032683 & 0.006537 & & \\
Total error & 27 & 2.258593 & 0.083652 & & \\
\hline
\end{tabular}

$\mathrm{DF}$, degrees of freedom

lack of fit was significant $(p=0.0032<0.05)$.

Next, the following trials were made for improving the second-order model. First, cubic terms were added to the second-order model, but this did not enhance the model. Second, three-way interaction terms were added to the second-order model, yet, the improvement made by this attempt was insufficient. Third, three-way and four-way interaction terms were added to the second-order model, and this augmented model turned out to be satisfactory (Table 4), as displayed by the ANOVA; the model was significant $(p=0.0001<0.05)$, the $r^{2}$ was high $\left(r^{2}=0.9646\right)$, and the lack of fit was nonsignificant $(p=0.1110>0.05)$. Thus, this model, with 5 linear, 5 quadratic, 10 two-way interaction, 10 three-way interaction, and 5 four-way interaction terms as its explanatory variables, was selected as the final model. The coefficients in this final model are indicated in Table 5 .

\section{Finding the optimum point of the factors}

Through a search on a grid [17], we maximized the predicted response from the model having the coefficients in Table 5. The bounds for the factor levels were $-\sqrt{5} \leqq X_{j} \leqq \sqrt{5}, j=1,2,3,4,5$, because the radius of the spherical region of the experimental design displayed in Table 2 was $\sqrt{5}$. Thus, with the intervals of $-\sqrt{5} \leqq X_{j} \leqq \sqrt{5}, j=1,2,3,4,5$, we made a search within the spherical region having the radius of $\sqrt{5}$ for which the constraint was $\mathrm{X}_{1}^{2}+\mathrm{X}_{2}^{2}+\mathrm{X}_{3}^{2}+\mathrm{X}_{4}^{2}+\mathrm{X}_{5}^{2} \leqq 5$. This search, which was conducted using SAS data-step programming, determined the optimum point described in Table 6, which states the estimated maximum of the response $\left(\log _{10} \mathrm{CFU} / \mathrm{mL}\right)$ as 10.265 .

Table 4. Analysis of variance for the final model

\begin{tabular}{lrcccc}
\hline \multicolumn{1}{c}{ Regression } & DF & Sum of squares & $\boldsymbol{R}$-square & $\boldsymbol{F}$-value & $\boldsymbol{p}$-value \\
\hline Linear & 5 & 1.601320 & 0.3190 & 21.60 & 0.0000 \\
Quadratic & 5 & 0.234238 & 0.0467 & 3.16 & 0.0476 \\
2-Way interactions & 10 & 0.926281 & 0.1845 & 6.25 & 0.0020 \\
3-Way interactions & 10 & 1.443231 & 0.2875 & 9.73 & 0.0002 \\
4-Way interactions & 5 & 0.637441 & 0.1270 & 8.60 & 0.0012 \\
Total model & 35 & 4.842511 & 0.9646 & 9.33 & 0.0001 \\
\hline \multicolumn{1}{c}{ Residual } & DF & Sum of squares & Mean square & $\boldsymbol{F}$-value & $\boldsymbol{p}$-value \\
\hline Lack of fit & 7 & 0.145237 & 0.020748 & 3.17 & 0.1110 \\
Pure error & 5 & 0.032683 & 0.006537 & & \\
Total error & 12 & 0.177921 & 0.014827 & & \\
\hline
\end{tabular}

$\mathrm{DF}$, degrees of freedom. 
Table 5. Coefficient estimates and related statistics in the final model

\begin{tabular}{|c|c|c|c|c|}
\hline Model terms & Coefficient estimate & Standard error & $t$-value & $p$-value \\
\hline Intercept & $b_{0}=9.2985270$ & 0.0492900 & 188.65 & $<.0001$ \\
\hline $\mathrm{X}_{1}$ & $b_{1}=0.0571540$ & 0.0185268 & 3.08 & 0.0095 \\
\hline $\mathrm{X}_{2}$ & $b_{2}=0.1615755$ & 0.0185268 & 8.72 & $<.0001$ \\
\hline$X_{3}$ & $b_{3}=-0.0249857$ & 0.0185268 & -1.35 & 0.2024 \\
\hline$X_{4}$ & $b_{4}=0.0745395$ & 0.0185268 & 4.02 & 0.0017 \\
\hline$X_{5}$ & $b_{5}=-0.0389546$ & 0.0185268 & -2.10 & 0.0573 \\
\hline$X_{12}$ & $b_{11}=-0.0087420$ & 0.0171463 & -0.51 & 0.6194 \\
\hline$x_{22}$ & $b_{22}=-0.0400034$ & 0.0171463 & -2.33 & 0.0379 \\
\hline$X_{32}$ & $b_{33}=-0.0114216$ & 0.0171463 & -0.67 & 0.5179 \\
\hline$X_{42}$ & $b_{44}=0.0439558$ & 0.0171463 & 2.56 & 0.0248 \\
\hline$X_{52}$ & $b_{55}=-0.0078488$ & 0.0171463 & -0.46 & 0.6553 \\
\hline$X_{1} \times X_{2}$ & $b_{12}=-0.0203125$ & 0.0215252 & -0.94 & 0.3640 \\
\hline$X_{1} \times X_{3}$ & $b_{13}=-0.0734375$ & 0.0215252 & -3.41 & 0.0052 \\
\hline $\mathrm{X}_{1} \times \mathrm{X}_{4}$ & $b_{14}=-0.0859375$ & 0.0215252 & -3.99 & 0.0018 \\
\hline$X_{1} \times X_{5}$ & $b_{15}=-0.0246875$ & 0.0215252 & -1.15 & 0.2738 \\
\hline$X_{2} \times X_{3}$ & $b_{23}=-0.0653125$ & 0.0215252 & -3.03 & 0.0104 \\
\hline $\mathrm{X}_{2} \times \mathrm{X}_{4}$ & $b_{24}=-0.0215625$ & 0.0215252 & -1.00 & 0.3362 \\
\hline$X_{2} \times X_{5}$ & $b_{25}=-0.0815625$ & 0.0215252 & -3.79 & 0.0026 \\
\hline$X_{3} \times X_{4}$ & $b_{34}=-0.0571875$ & 0.0215252 & -2.66 & 0.0209 \\
\hline$X_{3} \times X_{5}$ & $b_{35}=-0.0221875$ & 0.0215252 & -1.03 & 0.3230 \\
\hline$X_{4} \times X_{5}$ & $b_{45}=0.0003125$ & 0.0215252 & 0.01 & 0.9887 \\
\hline$X_{1} \times X_{2} \times X_{3}$ & $b_{123}=0.0690625$ & 0.0215252 & 3.21 & 0.0075 \\
\hline $\mathrm{X}_{1} \times \mathrm{X}_{2} \times \mathrm{X}_{4}$ & $b_{124}=-0.0234375$ & 0.0215252 & -1.09 & 0.2976 \\
\hline$X_{1} \times X_{3} \times X_{4}$ & $b_{134}=0.1021875$ & 0.0215252 & 4.75 & 0.0005 \\
\hline $\mathrm{X}_{2} \times \mathrm{X}_{3} \times \mathrm{X}_{4}$ & $b_{234}=0.0478125$ & 0.0215252 & 2.22 & 0.0463 \\
\hline$X_{1} \times X_{2} \times X_{5}$ & $b_{125}=0.0103125$ & 0.0215252 & 0.48 & 0.6405 \\
\hline$X_{1} \times X_{3} \times X_{5}$ & $b_{135}=0.0559375$ & 0.0215252 & 2.60 & 0.0233 \\
\hline$X_{2} \times X_{3} \times X_{5}$ & $b_{235}=0.1403125$ & 0.0215252 & 6.52 & $<.0001$ \\
\hline$X_{1} \times X_{4} \times X_{5}$ & $b_{145}=0.0321875$ & 0.0215252 & 1.50 & 0.1607 \\
\hline$X_{2} \times X_{4} \times X_{5}$ & $b_{245}=0.0478125$ & 0.0215252 & 2.22 & 0.0463 \\
\hline$X_{3} \times X_{4} \times X_{5}$ & $b_{345}=0.0284375$ & 0.0215252 & 1.32 & 0.2111 \\
\hline $\mathrm{X}_{1} \times \mathrm{X}_{2} \times \mathrm{X}_{3} \times \mathrm{X}_{4}$ & $b_{1234}=-0.0003125$ & 0.0215252 & -0.01 & 0.9887 \\
\hline$X_{1} \times X_{2} \times X_{3} \times X_{5}$ & $\mathrm{~b}_{1235}=-0.0440625$ & 0.0215252 & -2.05 & 0.0632 \\
\hline $\mathrm{X}_{1} \times \mathrm{X}_{2} \times \mathrm{X}_{4} \times \mathrm{X}_{5}$ & $b_{1245}=0.0646875$ & 0.0215252 & 3.01 & 0.0110 \\
\hline$X_{1} \times X_{3} \times X_{4} \times X_{5}$ & $b_{1345}=-0.0984375$ & 0.0215252 & -4.57 & 0.0006 \\
\hline $\mathrm{X}_{2} \times \mathrm{X}_{3} \times \mathrm{X}_{4} \times \mathrm{X}_{5}$ & $\mathrm{~b}_{2345}=-0.0640625$ & 0.0215252 & -2.98 & 0.0116 \\
\hline
\end{tabular}

Table 6. Optimization results for the maximization of the response

\begin{tabular}{cccccccccc}
\hline $\begin{array}{c}\text { Estimated } \\
\text { maximum of the } \\
\text { response }\end{array}$ & $X_{1}$ & $X_{2}$ & $X_{3}$ & $X_{4}$ & $X_{5}$ & $\begin{array}{c}\text { Soy } \\
\text { peptone } \\
(\%)\end{array}$ & $\begin{array}{c}\text { Yeast } \\
\text { extract } \\
(\%)\end{array}$ & $\begin{array}{c}\text { Glucose } \\
(\%)\end{array}$ & $\begin{array}{c}\text { L-Cysteine } \\
(\%)\end{array}$ \\
\hline 10.265 & 0.95 & 1.04 & 0.90 & -1.03 & -1.07 & 2.8030 & 2.8791 & 0.6196 & 0.2823 \\
\hline
\end{tabular}




\section{Drawing response surface contour plots}

A plot of response surface contours was drawn for two of the five factors; the vertical axis and the two horizontal axes represented the response predicted from the model and the actual levels of the two explanatory factors, respectively. Fig. 1 contains all 10 such plots. In each plot, the factors not

(a)

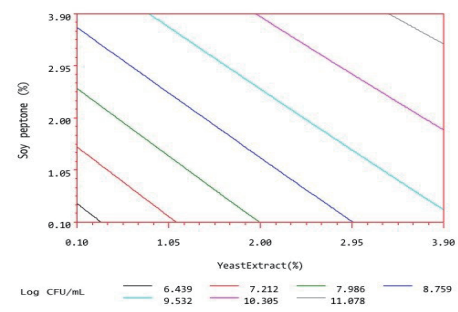

(c)

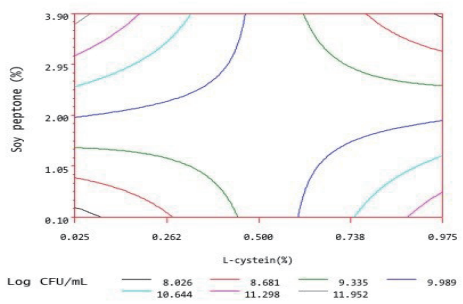

(e)

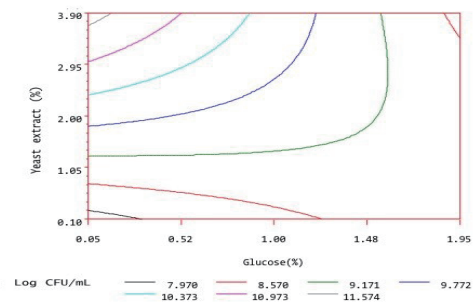

(g)

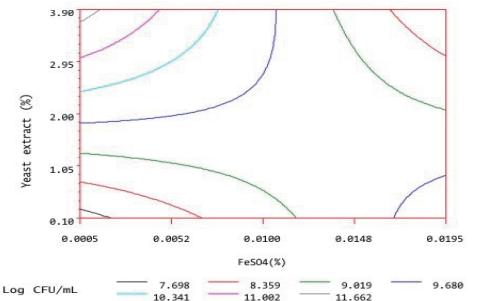

(i)

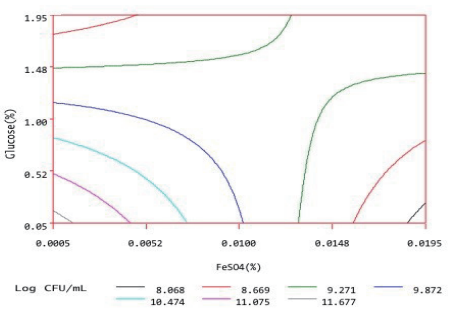

(b)

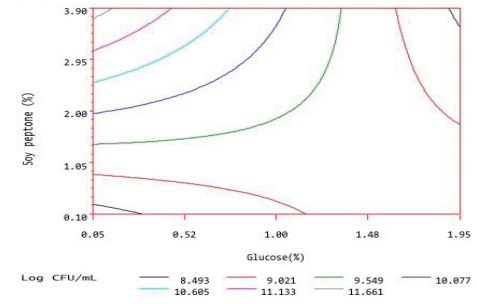

(d)

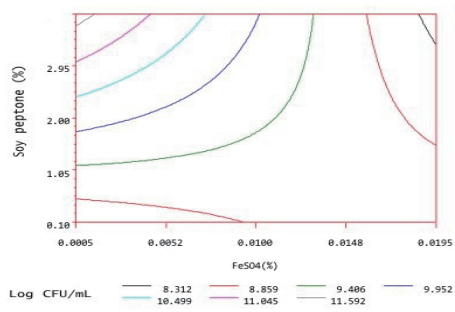

(f)

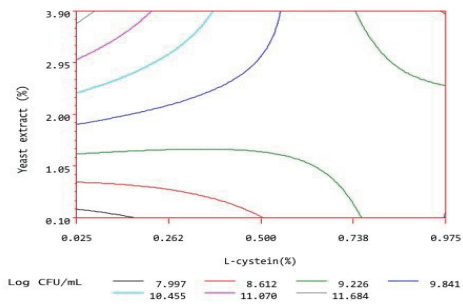

(h)

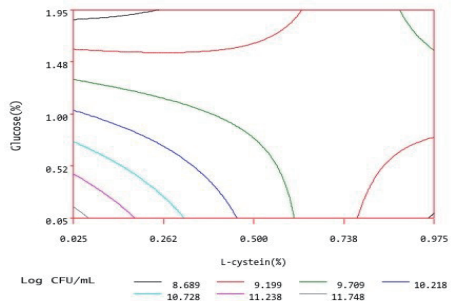

(j)

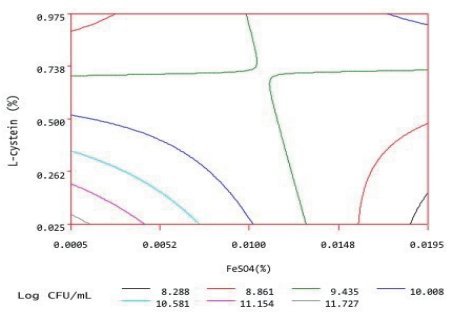

Fig. 1. Response surface contour plots of maximum biomass as the function of components. (a) soy peptone and yeast extract, (b) soy peptone and glucose, (c) soy peptone and L-cystein, (d) soy peptone and ferrous sulfate, (e) yeast extract and glucose, (f) yeast extract and L-cystein, (g) yeast extract and ferrous sulfate, (h) glucose and L-cystein, (i) glucose and ferrous sulfate, (j) L-cystein and ferrous sulfate. 
represented by the two horizontal axes are fixed at their optimum actual levels.

\section{Experimenting for validation}

To measure the adequacy of the model (Table 7), a validation experiment was performed at the optimum point of $2.8791 \%$ yeast extract, $2.8030 \%$ peptone soy, $0.6196 \%$ glucose, $0.2823 \%$ L-cysteine, and $0.0055 \%$ ferrous sulfate, to verify the validity of the optimum medium. Besides, to assess the application potential in manufacturing, it was appropriate to test the mass cell- producing ability of several organism strains as well as assess the economical optimization of the medium. Therefore, three bifidobacterial strains including B. longum ATCC 15907, B. bifidum ATCC 35914 and B. aminalis subsp. lactis BB12 were used in cell count evaluation as well.

The maximum biomass production at $20 \mathrm{~h}$ incubation of bifidobacteria strains was expressed via Fig. 2 and the economical-effect of optimum medium was calculated and shown in Table 7. Fig. 2 showed that in the two media, the numbers of viable cells of all bacterial strains after a 20 h-incubation were similar and there were no concrete differences between the two media. Moreover, the price for producing 250 liters of the media was $\geq \$ 100$ US dollars less than the same volume of the BL broth; the new medium costs $79.04 \%$ the price of the BL medium (Table 7).

\section{DISCUSSION}

In a similar research to optimize growth conditions of Bifidobacterium pseudocatenulatum $\mathrm{G} 4$, a candidate probiotic organism achieved a maximum biomass production of $9.129 \log _{10} \mathrm{CFU} / \mathrm{mL}$ [9].

Table 7. Optimum medium and the results of the validation experiment

\begin{tabular}{|c|c|c|}
\hline Components & BL medium (\%) & Optimum medium (\%) \\
\hline Meat extract & 0.3 & -1) \\
\hline Proteose peptone No.3 & 1 & - \\
\hline Trypticase & 0.5 & - \\
\hline Peptone & 0.3 & 28.030 \\
\hline Yeast extract & 0.5 & 28.791 \\
\hline Liver extract (mL) & 15 & - \\
\hline Glucose & 1 & 6.196 \\
\hline Soluble starch & 0.05 & - \\
\hline Potassium phosphate buffer $(\mathrm{mL})$ & 1 & - \\
\hline $\mathrm{K}_{2} \mathrm{HPO}_{4}$ & 0.1 & - \\
\hline $\mathrm{KH}_{2} \mathrm{PO}_{4}$ & 0.1 & - \\
\hline Mineral mixture $(\mathrm{mL})$ & 0.5 & - \\
\hline $\mathrm{MgSO}_{4}$ & 0.001 & - \\
\hline $\mathrm{FeSO}_{4}$ & 0.02 & 0.055 \\
\hline $\mathrm{NaCl}$ & 0.000674 & - \\
\hline $\mathrm{MnSO}_{4}$ & 0.001 & - \\
\hline Tween 80 & 0.1 & - \\
\hline L-Cysteine & 0.05 & 2.823 \\
\hline Distilled water (mL) & 1,000 & 1,000 \\
\hline Price for 250 litters of broth (USD) & 515.684 & 407.638 \\
\hline Cost effect (\%) & - & 79.04 \\
\hline
\end{tabular}

${ }^{1)}$ Absence of constituent

$\mathrm{BL}$, blood-liver. 


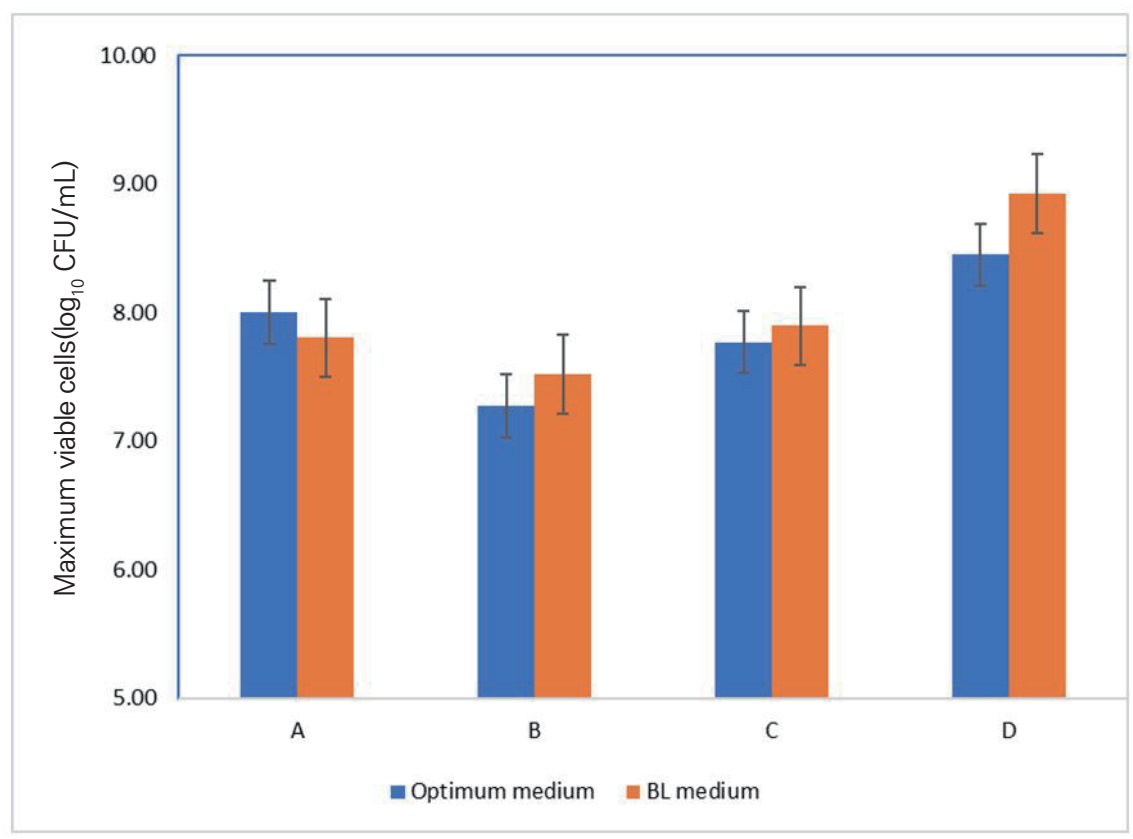

Fig. 2. Biomass production of different bifidobacteria strains in optimized medium and BL medium after 20 h fermentation. (A) Bifidobacterium animalis subsp. lactis JNU306, (B) B. longum ATCC 15907, (C) B. bifidum ATCC 35914, (D) B. aminalis subsp lactis BB12. BL, blood-liver.

Hussain et al. [17] recently reported on the optimal growth conditions of B. bifidum in small scale fermentation, and observed the maximum wet-cell weight at optimized growth condition was 34.1 $\mathrm{g} / \mathrm{L}$. The final viable cells increased to $9.398 \log _{10} \mathrm{CFU} / \mathrm{mL}$ under constant $\mathrm{pH}$ condition.

Besides, many intensive studies have been conducted on aspect finding optimized medium for maximum biomass production of many different bacterial species via different parameters such as viable cells $\log _{10} \mathrm{CFU} / \mathrm{mL}[9,18,19]$, maximum specific growth rate per hour [20] or dry cell weight, gram per liter [21]. Thus, in comparison with these published papers, the result of this study is limited. Furthermore, since growth performance is a specific strain, which was very popularly used in manufacturing the optimum medium should be compared on commonly used commercial media with the individual strain.

To test the mass cell-producing ability of several bacterial strains, the maximum biomass obtained from the optimized medium was compared with growth performance in BL broth, which is frequently used as optimal medium [15].

In the two media, the numbers of viable cells of all bacteria were similar and there were no practical differences between the two media. These results suggested the applicability of the optimum medium. Moreover, the cost of the new medium is lower than that of BL medium. These results confirmed that our new optimum medium has potential application in manufacture.

\section{CONCLUSIONS}

The use of a new response surface approach as a statistical tool to improve the growth of B. animalis subsp. lactis strain JNU306 within yeast extract, soy-peptone, glucose, L-cysteine, and ferrous sulfate components has been demonstrated in this study. This work has developed a statistical model to assess the third-order polynomial effects between components and established their estimated 
optimum levels to maximize biomass production. One of the highest viable cell counts was observed: the optimum point was $2.8791 \%$ yeast extract, $2.8030 \%$ soy-peptone, $0.6196 \%$ glucose, $0.2823 \% \mathrm{~L}$-cysteine, and $0.0055 \%$ ferrous sulfate. Through a validation experiment, the optimum medium turned out to be economically viable in that its cultivation amount was the same but production was more cost-effective than BL medium.

\section{REFERENCES}

1. Arunachalam KD. Role of bifidobacteria in nutrition, medicine and technology. Nutr Res. 1999;19:1559-97.https://doi.org/10.1016/S0271-5317(99)00112-8

2. Dave RI, Shah NP. Evaluation of media for selective enumeration of Streptococcus thermophilus, Lactobacillus delbrueckii ssp. bulgaricus, Lactobacillus acidophilus, and bifidobacteria. J Dairy Sci. 1996;79:1529-36. https://doi.org/10.3168/jds.S0022-0302(96)76513-X

3. Masco L, Huys G, De Brandt E, Temmerman R, Swings J. Culture-dependent and culture-independent qualitative analysis of probiotic products claimed to contain bifidobacteria. Int J Food Microbiol. 2005;102:221-30. https://doi.org/10.1016/j.ijfoodmicro.2004.11.018

4. Ventura M, Canchaya C, Van Sinderen D, Fitzgerald GF, Zink R. Bifidobacterium lactis DSM 10140: identification of the atp (atpBEFHAGDC) operon and analysis of its genetic structure, characteristics, and phylogeny. Appl Environ Microbiol. 2004;70:3110-21. https:// doi.org/10.1128/AEM.70.5.3110-3121.2004

5. Sánchez B, Champomier-Vergès MC, Stuer-Lauridsen B, Ruas-Madiedo $P$, Anglade $P$, Baraige $\mathrm{F}$, et al. Adaptation and response of Bifidobacterium animalis subsp. lactis to bile: a proteomic and physiological approach. Appl Environ Microbiol. 2007;73:6757-67. https://doi. org/10.1128/aem.00637-07

6. Barrangou R, Briczinski EP, Traeger LL, Loquasto JR, Richards M, Horvath P, et al. Comparison of the complete genome sequences of Bifidobacterium animalis subsp. lactis DSM 10140 and B1-04.J Bacteriol. 2009;191:4144-51. https://doi.org/10.1128/JB.00155-09

7. Taipale T, Pienihäkkinen K, Isolauri E, Larsen C, Brockmann E, Alanen P, et al. Bifidobacterium animalis subsp. lactis BB-12 in reducing the risk of infections in infancy. Br J Nutr. 2011;105:409-16. https://doi.org/10.1017/S0007114510003685

8. Bezcorovainy A, Catchpole RM. Biochemistry and physiology of bifidobacteria. Boca Raton, FL: CRC press; 1989.

9. Stephenie W, Kabeir BM, Shuhaimi M, Rosfarizan M, Yazid AM. Growth optimization of a probiotic candidate, Bifidobacterium pseudocatenulatum G4, in milk medium using response surface methodology. Biotechnol Bioprocess Eng. 2007;12:106-13. https://doi.org/10.1007/ BF03028634

10. Rašić J, Kurmann JA. Bifidobacteria and their role: microbiological, nutritional-physiological, medical and technological aspects and bibliography. Basel: Birkhäuser Verlag; 1983.

11. Montgomery DC. Design and analysis of experiments. Hoboken, NJ: John Wiley \& Sons; 1984.

12. Bezerra MA, Santelli RE, Oliveira EP, Villar LS, Escaleira LA. Response surface methodology (RSM) as a tool for optimization in analytical chemistry. Talanta. 2008;76:965-77. https://doi. org/10.1016/j.talanta.2008.05.019

13. Khuri AI, Mukhopadhyay S. Response surface methodology. Wiley Interdiscip Rev Comput Stat. 2010;2:128-49. https://doi.org/10.1002/wics.73

14. Brown M, Foster JHS. A simple diagnostic milk medium for Pseudomonas aeruginosa. J Clin Pathol. 1970;23:172-7. https://doi.org/10.1136/jcp.23.2.172 
15. Ochi Y, Tomottari M. Studies on Lactobacilli. Jpn J Vet Sci. 1958;20:71-81. https://doi. org/10.1292/jvms1939.20.71

16. SAS Institute. SAS/STAT user's guide, release 6.04. Cary, NC: SAS Institute, 1986.

17. Hussain SM, Naik M, Ahmed LA, Udipi M, Sukumaran SK. Bioprocess development for enhanced production of probiotic Bifidobacterium bifidum. Current Sci. 2020;118:280-5.

18. Oh S, Rheem S, Sim J, Kim S, Baek Y. Optimizing conditions for the growth of Lactobacillus casei YIT 9018 in tryptone-yeast extract-glucose medium by using response surface methodology. Appl Environ Microbiol. 1995;61:3809-14. https://doi.org/10.1128/AEM.61.11.38093814.1995

19. Liew S, Ariff AB, Raha AR, Ho YW. Optimization of medium composition for the production of a probiotic microorganism, Lactobacillus rhamnosus, using response surface methodology. Int J Food Microbiol. 2005;102:137-42. https://doi.org/10.1016/j.ijfoodmicro.2004.12.009

20. Kiviharju K, Leisola M, Eerikäinen T. Optimization of a Bifidobacterium longum production process.J Biotechnol. 2005;117:299-308. https://doi.org/10.1016/j.jbiotec.2005.02.007

21. Sen R, Babu KS. Modeling and optimization of the process conditions for biomass production and sporulation of a probiotic culture. Process Biochem. 2007;40:2531-8. https://doi. org/10.1007/BF03028634 